\title{
What is Living and What is Non-Living in Merleau-Ponty's Philosophy of Movement and Expression
}

David Morris, Department of Philosophy, Concordia University, davimorr@alcor.concordia.ca

Published in Chiasmi International: Trilingual Studies Concerning Merleau-Ponty’s Thought 7 (2006): 225-239

http://philosophy.memphis.edu/Chiasmi_International/index.htm

Abstract:

Ancient philosophy models non-living processes in terms of living beings; modern science and philosophy reverses this priority by conceiving the living as evolving from the non-living. Recent work in science and philosophy questions that reversal, by emphasizing how living beings are self-organizing, active agencies. But in the contemporary context we would need a new concept of nature to follow through on this reversal, to fit self-organizing organisms with nature as a whole.

A study of the themes of structure, expression and sense across Merleau-Ponty's philosophy opens a way toward this new concept. Points from Bergson and Hegel lead to a concept of expression as a movement that creates new possibility. Results from immunology and evolutionary cellular biology let us detect such a movement of sense in nature. This gives a model for thinking of nature as a whole as an expressive, living movement-for thinking of the law of the non-living as the visible outgrowth of an invisible expressive movement of the universe.

In ancient philosophy, life is primary. ${ }^{1}$ For example, for Aristotle, moving, growing organisms are exemplary of substance and movement, central terms of Aristotle's metaphysics and physics. ${ }^{2}$ The non-living is made intelligible on the model of the living. But modern skepticism wears down all appeal to an outside intelligibility, and remodels the outer world on the inner light of reason. Given the tools and procedures with which modern scientific reason begins, the fundamental terms in the new models end up being static, inert. ${ }^{3}$ The living is thus made intelligible on the model of the non-living.

The reversal from the primacy of the living to the primacy of the non-living is made feasible by Darwin and the modern evolutionary synthesis. In his magisterial analysis, The Structure of Evolutionary Theory, Stephen Jay Gould notes that prior to Darwin, biologists had recognized adaptation via natural selection, but took this process as only being able to discard already given organic forms: natural selection can improve by weeding out, but cannot create biological form. Darwin's central accomplishment is giving a convincing account of how a non-creative process of natural selection can, over a very long time, granted mechanisms of inherited variation, be creative of biological form. ${ }^{4}$ The modern synthesis shows how genetics is at the basis of heritable variation, and thereby finds a way of understanding the living as the historical outcome of non-creative processes that can be understood chemically. The living is thus rooted in the non-living.

But the reversal overshoots and goes back in the direction of the living. The effort of reducing biological form to a product of genetics in fact convinces scientists that genetic information is not enough to specify organic form. The patterns of leaf organization that pervade the plant world, for example, do not simply or ultimately point to a genetically encoded pattern common to and inherited by all plants, but to a common morphogenetic process: tensions inherent in the structured dynamics of plant growth, not mere genetics, generate the basic patterns of leaf organization. Likewise with the bone structure of vertebrate limbs. ${ }^{5}$ The usual tendency of physics and science is to 
construe living beings as special and rare cases to be understood in terms of more general physical systems; in contrast, Robert Rosen has argued that understanding living beings as physical systems requires a new sort of physical formalism that emphasizes relations, rather than entities; he has worked out this formalism in detail, and within it, it is the non-living that is special and rare, since non-living entities are conceived as closed and static systems to be isolated within larger, self-organizing, open systems. ${ }^{6}$ Indeed, in contemporary science and philosophy, activity and agency, relation and process, crop up everywhere, displacing passive matter and abstract law. ${ }^{7}$ And in Manuel Delanda's recent reconstruction of Deleuze, contra the modern injunction that reason is only truly manifest to the interiority of subjectivity, we find an intelligibility that creates itself in movement, an intelligibility that is not interior to reason but is in things themselves, what I shall call an intelligibility of the outside. ${ }^{8}$ Maxine Sheets-Johnstone's insistence on an intelligibility within animate form echoes this intelligibility of the outside. ${ }^{9}$ These scientists and philosophers swing us back in Aristotle's direction. Both the living and the non-living make themselves intelligible as self-organizing processes-processes exemplified by the living but also found in the non-living. But in the age of technological reason, of calculable, controllable nature, it seems all too outrageous to think of nature not as clockwork but as life-like. How are we to think this?

In this paper I want to indicate how Merleau-Ponty's philosophy of expression can be a resource for rethinking nature and life. In the first sections I briefly indicate the role of self-organization and expression across Merleau-Ponty's philosophy. In the second section I link expression to movement. The link between expression and movement opens the way for some suggestions, in the final section, about how nature as a whole involves expressive movement and is in this sense living. My conceptual explorations are motivated by Renaud Barbaras's indication, in "The Movement of the Living as the Originary Foundation of Perceptual Intentionality," that reconciling the phenomenon of life with nature would require a new way of thinking nature, not a reduction of living movement to nature as typically conceived by the physicist. ${ }^{10}$ They are also inspired by Maxine SheetsJohnstone's turn to animate movement. ${ }^{11}$

\section{Structure, expression and sense in Merleau-Ponty's philosophy}

Very often the effort of putting MerleauPonty's works together is organized around their chronology, in which case his conceptual advances seem to accumulate in a break between an earlier and later Merleau-Ponty. But it would equally be possible to grasp his works as cohering around a single problem, which I call the problem of structure, sense and expression. ${ }^{12}$ The Structure of Behaviour discovers this problem by arguing that a science of behaviour is possible only if there is structure. ${ }^{13}$ As we shall see, the concept of structure raises the problem of perception, the beginning point of the

Phenomenology. ${ }^{14}$ The Phenomenology argues that perceptual experience is possible only if there is a pre-personal sense expressed in gesture, the body, words, etc. This concept provokes a rather Bergsonian difficulty: how can philosophy speak of a pre-personal sense? In trying to speak of the pre-personal, is not philosophy rather like a ventriloquist who insists that really, it is the dummy who is doing the talking? The Visible and the Invisible begins with this problem and tries to solve it by re-installing 
philosophical interrogation in being, thus showing how, indeed, being is not dumb but itself foreshadows sense and philosophical interrogation. ${ }^{15}$ Returning interrogation and sense to being requires concepts such as chiasm, dehiscence, reversibility and écart, which amount to radical new ways of grasping expression and sense as going all the way down to the roots of being, rather than understanding expression and sense as subsequent, subjective impositions on being - the Cartesian position. Put this way, Merleau-Ponty's stated problem with his early work, that it wrongly persists in starting from the consciousness-object division, is really a symptom of a deeper problem, namely a failure to locate structure and sense in being itself. ${ }^{16}$ Merleau-Ponty's philosophy thus sets him the task of rooting expression in nature-and it is precisely because of this that his philosophy can be a resource for rethinking life and nature.

To give a better indication of this approach to Merleau-Ponty and the problem of expression and nature, let me briefly return to The Structure of Behaviour and the Phenomenology. Structure shows how the extremes of idealism and realism fail to grasp the phenomenon of behaviour. The way out is structure, "the joining of an idea and an existence which are indiscernible, the contingent arrangement by which materials begin to have sense in our presence, intelligibility in the nascent state." ${ }^{17}$ In other words, in structures Merleau-Ponty finds an intelligibility of the outside. But if there is to be an intelligibility in things, then things must be what we would now call selforganizing. This phenomenon is familiar in the vital and human orders: organisms construct their own norms over the life-time of species; language and other cultural objects organize new meaning over individual lifetimes. But crucially, in Structure Merleau-Ponty also conceives the physical order as self-organizing. For example, in a detailed analysis of what he calls "dynamic structure” Merleau-Ponty argues that "elements or particles" are not invested with "absolute properties"; they do not form structures because of already specified "intersecting...linear causal series.” Rather, it is because particles form a “"'molar” individual”" that their laws "express" a structure, and the laws and properties of particles are intelligible only within structures. So "science must be linked to a history of the universe in which the development is discontinuous," that is, nature is not the unwinding of already specified laws, but a development punctuated by the creation of new sorts of individual collectivities (SdC 148-9/138-40). When studying these passages in Structure, it is hard not to see an anticipation of some aspects of recent science and Deleuzian philosophy. ${ }^{18}$

But Merleau-Ponty diverges from Deleuzianism because he argues that "form is not a physical reality, but an object of perception” (SdC 155/143). At this point, careful study of Structure reveals a crucial tension within Merleau-Ponty. On the one hand, since form, or structure, is an object of perception, nature must expand to include the human order in which perception and language express the implicit, nascent sense of structure, which means that nature itself must have a sense, there must be an intelligibility of the outside. ${ }^{19}$ On the other hand, despite Merleau-Ponty's tendency in Structure, perhaps learned from Bergson, to question anthropomorphic interpretations of concepts $^{20}$, structure only becomes fully explicit when expressed in a human language that has an autonomous sense. And, as we know, since the reality of structure is in perception, The Structure of Behaviour ends with a call for a study of perception. In other words, in resolving the ontological problem of structure - of how there can be a dynamic, self-organizing 
sense in nature - there is a tension between localizing expression and sense within the human order, and rooting expression, sense and the human order in a nature that itself has sense.

The Phenomenology of Perception only deepens this tension. In rejecting the ready-made world and transcendental consciousness, Merleau-Ponty once again turns to something like structure, to a meaning nascent in the world. He finds this meaning by discovering a new sort of sense within gesture, by discovering the body schema, in short, by discovering that bodily movements in the world have a pervasively self-organizing character that already has (or is) a pre-personal sense. But once again, expression - the body as expressive, perception as expressive, language as expressive-are central in bringing this prepersonal sense to light. To take this back to the beginning of the Phenomenology, sense is not introjected into the world by a free floating transcendental consciousness, rather the perceiver inheres in a transcendental field and sense arises within this field. Here I am drawing on Leonard Lawlor's work on expression $^{21}$, which work reminds us that for Merleau-Ponty the sense of the transcendental field arises in "a creative operation which itself participates in the facticity of...experience." (PhP 74/61) This creation of sense within non-sense, of structure, is nothing other than primary expression. $^{22}$ Sense, expression and structure thus entwine within the transcendental field. And Lawlor shows how the balance between Merleau-Ponty and Deleuze hangs on the question of how expression is "anticipated" in the "unreflective experience" from which the transcendental field arises-Merleau-Ponty can escape the Deleuzian criticism only if the relation between sense and non-sense is immanent within the field, rather than in subjectivity.
Put otherwise, Merleau-Ponty opens the question how can there already be a sense in nature, rather than in the subject merely, a question he pursues in the Visible and the Invisible. But here I want to pursue this question by drawing a connection between expression and movement via the Phenomenology.

\section{Expression as Movement}

Bernard Waldenfels's article "The Paradox of Expression” exposes the paradoxical core of Merleau-Ponty's concept of expression. ${ }^{23}$ By juxtaposing Merleau-Ponty with Deleuze, Leonard Lawlor's article “The End of Phenomenology: Expressionism in Merleau-Ponty and Deleuze” helps sharpen this paradox. For Deleuze, "[t]he paradox is that at once 'the expressed' does not exist outside of the expression and yet bears no resemblance to it” (Lawlor, 17). As Lawlor shows, what is ontologically at stake in Deleuze's expressionism is a ground that "must never borrow characteristics from what it grounds," that "must presuppose nothing of what it engenders.” (Lawlor, 22) But this paradoxical ground is definitive of primary expression in Merleau-Ponty: I am trying to find words that would express what I am trying to think, yet what I am trying to think is not at all clear until I express myself; the silence prior to expression does not contain the expression that it engenders. What ends up being expressed stems from an engendering silence, yet bears no resemblance to it. This kind of expression, which Merleau-Ponty calls primary expression, is a fundamentally creative operation. (In the rest of the paper, primary expression is the sole concern.)

Empirically, the phenomenon of expression is obviously a phenomenon of movement, since it involves making a mark in the world, and that requires a change of place, quality, quantity or something new 
coming into being, movement in Aristotle's sense. ${ }^{24}$ But I want to suggest a deeper, ontological affinity between expression and movement. Here are my reasons, which stem from the peculiar logic of expression.

1) Expression is a relation between moments of one continuous expression. Yet this relation is not one of resemblance, since the continuity of expression is punctuated by discontinuity, by the creation of a difference. So expression involves what Bergson would call transference of a state ${ }^{25}$, a real movement. Put another way, the beginning and end of expression do not have the sort of identity of mathematical points that can be translated onto one another within an already defined plane. To draw once again on Bergson, the beginning and end of expression are juxtaposed in the manner of a child and the adult she becomes. The adult is not something other than the child, yet does not resemble the child, since the child does not contain the adult. The beginning and end of expression are not related by a mechanical translation within a plane, but by a creative movement that transforms the plane from within. As Merleau-Ponty puts it, expression creates the inner text that it translates. $^{26}$ The creative 'translation' we are talking about here is the sort of "bouleversement" of the child learning the difference between red and blue ( $P h P$ $38 / 30$ ), the sort of creative operation that elaborates the transcendental field ( $P h P$ $74 / 61)$. What goes on in expression is what goes on in a real movement.

2) A similar point follows from the Bergsonian and Merleau-Ponteian claim that real movement is a whole irreducible to its parts. In a peculiar way, to become a beginning, the beginning of a movement has to wait for the whole of movement. When I wander out the front door, my steps are not really the beginning of a walk until I wind up back at home after having taken a walk; at a given moment I could decide to dance or go to the café, in which case my initial steps would not have been the beginning of a walk. The point that the beginning of the movement must wait for the whole of movement is much clearer in gesture: the beginning of a gesture is not yet really the beginning of a gesture until it unfurls in gestural expression. Even though a movement is a continuous whole, or precisely because it can only be a whole, there is a peculiar discontinuity between the moments of movement and the movement as a whole. This is just the sort of paradoxical relation we find between the expressed and the expression.

So far I have been trying to show an affinity between the ontology of movement and the peculiar logic of expression. But I want to go further in making sense of expression as movement. There would be a way of doing this phenomenologically ${ }^{27}$, but I want to head in an ontological direction. To do that I wrest a clue from Hegel's Science of Logic, in light of Bergson's link between movement and possibility. (Bergson is behind both Merleau-Ponty and Deleuze, as is Hegel, via Hyppolite.) The clue stems from Hegel's demonstration that abandoning the logic of transcendental reflection-Merleau-Ponty's radical project in criticizing the ready-made worldrequires finding a ground that does not borrow from what it grounds, and this in turn requires a rethinking of the possible. (I leave the details to a note about this clue. ${ }^{28}$ ) If existence does not reflect a transcendental essence, then existence must actualize itself, that is, reflect its own possibilities. But if we think of possibility as a ready-made storehouse waiting to be unpacked, we turn possibility into a new version of transcendental essence. Here Hegel and Bergson converge in urging us to think of actuality as somehow productive of possibilities that enable new actualities. Bergson pursues this productive operation in 
terms of durée and creation. ${ }^{29}$ Hegel tries to grasp this operation as self-mediating, and calls it concept, what conceives itself, which Hyppolite (in Logique et existence) calls sense. The clue, finally, is that sense emerges and is found in processes that involve the actualization and the creation of possibility, as co-implicated in one another.

To give an example, when Joyce writes Finnegans Wake he does not just actualize existing possibilities of English, he re-possibilizes English and finds new actualities within this re-possibilization, the one by way of the other. Joyce begins with possibilities that are as it were 'stored' in actual English, but in writing the Wake, he opens new possibilities unanticipated in "English as she is spoke." 30 He does this only by not actualizing other heretofore unanticipated possibilities. It becomes significant that, for example, Joyce writes "[a]s we there are," rather than "[a]s we there am”-although neither sentence belongs to the 'store' of already possible English sense. The actualization of an unanticipated possibility is also the nonactualization of another, different unanticipated possibility; each new expression that Joyce develops at the edge of English is enhaloed by other expressions that are not even expressed. Each of Joyce's actualizations of what had not yet been possible in English thus does two things: it creates a new possibility by actualizing it for the first time; and it delimits the space of possibility within which the new possibility is actualized, by contrasting the new possibility with further possibilities that are not even not-actualized. (The complexity of this point stems from difficulties and insufficiencies of our usual concepts of actuality and possibility. ${ }^{31}$ ) This process, which I call re-possibilization, is not a movement into unexplored realms of an already existing storehouse of possibility, it is a movement of actualizing that reconfigures possibility by having actuality move toward a new outside in a way that diverges from a 'road not taken.' Novel sense is created by divergence from its ground in its own non-sense.

The connection between sense and the possible invites a characterization of expression as movement, which will help clarify the point just made. The science of information theory conceives information as the elimination of possibilities; the code for the letter " $\mathrm{B}$ " in an email is information because it eliminates the other 255 possible characters that could be there; the email "BUY IBM" is information so far as it eliminates the possibility of buying AT\&T, and so on. Email moves electrons so as to coordinate possibility elimination across space and time. Clearly this sort of possibility elimination is what MerleauPonty calls secondary expression. But suppose somebody emails you Finnegans Wake. What the hell does it mean? Joyce's language contrasts itself with possibilities that had not yet been considered; in his work the creation and elimination of possibilities are thoroughly blended. This is what is distinctive of primary expression as a movement: at one and the same time it verges into new moving possibilities and restricts them. ${ }^{32}$ Repeating a standard gesture is a secondary expression that communicates information by not being another gesture in an existing repertoire. In contrast, a spontaneous gesture is a primary expression of new sense because it at once and constantly verges toward newly possible movements, yet does not pursue them. It develops a trajectory within a movement space it itself creates. Think of a child inventing a dance: she does not have a space of possible movement in mind in advance, rather her actual movements at once decide a new way of moving and indicate moves not taken, moves that had not even been suggested as explicit possibilities in advance 
of her actual movements. The sense of the dance arises as it were in the wake of movement, in its divergence away from movements not-even-taken. And perhaps this phenomenon of sense arising in the divergence of movement is what MerleauPonty means to indicate by écart.

\section{Expressive Nature, Living Nature}

It is easy enough to see how expressive movement belongs to the human order. The question that the entirety of Merleau-Ponty's work leaves us with is whether such expressive movement, as it has here been conceived, arises in nature itself.

I am going to say it does. The vertebrate immunological system distinguishes between organism and invaders. But according to immunology this system is not a machine for checking biological tags against a fixed library of possible pathogens; rather it is a network of recursive interactions that continually creates a distinction between self and other. The immune system learns, and this means that contact with a novel pathogen must at once open a new space of possible responses, and restrict responses. The immune system does not just eliminate fixed possibilities, it actualizes itself by repossibilizing its movements. ${ }^{33}$ The immune system encountering something beyond its limits as a pathogen is, in a way, akin to Joyce encountering something beyond the limits of English as having a new sense within English. In this way, as MerleauPonty might put it, the immune system expresses the sense of self. ${ }^{34}$ To give another example, evolutionary theory no longer takes the reproduction and individuality of multicelluar organisms for granted, it seeks their explanation. According to the scientist Leo Buss, multicellular reproduction and individuality are counterpart phenomena. At a certain point in evolution, cilia, moving fibres, diverge in function: some move to the outside of cells, where they can move the cell in the environment; some move to the inside, where they can move the inner environment in preparation for reproduction. To get a multicellular creature that both reproduces and moves around, what is required is a cluster in which exterior cells with outside cilia do the moving and inner cells with inside cilia do the reproducing. This divergence between exterior and interior cilia within one creature entails a divergence between developmental layers, the division of the organism into inner and outward layers; this division serves as the template for the developmental structure and corresponding strata of cellular specialization familiar in earthly multicellular creatures, especially the divergence between germ and somatic cell lines, which is crucial to our sense of the individuality of multicellular creatures. ${ }^{35}$ Again, this crucial development does not follow from stored up possibilities; it actualizes itself by creating a new space of diverging possible movements for ciliaand divergences of inner and outer layers, structures and cell lines follow.

The case of the multicellular organism shows how something like expression-asmovement happens in the living. But does it happen in what we consider non-living? Another living example will help us pursue this question. A given, individual bird comes to migrate from one place to another only by following birds that already know crucial landmarks. A given bird in an established migration thus picks up information from the birds it follows (go this way, not that). But if we ask how a population of birds learns its migratory path for the first time, we find sense, not information; some birds had to venture forth, re-possibilizing movement by actualizing just some new movement possibilities. In the lifetime of an 
individual bird, the migratory path manifests a fixed route between already established points, and learning it means learning information. But in the lifetime of the flock, the path is learnt by creating it, the flockmovement creates a sense that is originally expressed.... and then expressed again in seasonal movement patterns.

Now imagine that the universe is like that, that space, time and laws do not manifest fixed routes of reality, but are the creation of a flock of movements over the single, long season of the universe. Imagine that space is not the inflation of an already established bubble of space, in which case we would end up with the logical difficulty of needing some prior space-time in which to conceive this inflation as happening. Imagine that space is what happens when certain swarms of movement migrate one after another, creating and actualizing possibilities. Conceive, if you will, that law, space and time, are not a causal container for movements, but the product of a prior kind of migratory movement, a migratory movement which could not be understood "extensively" in terms of a prior space and time, but "intensively."

What does this mean? In the Structure of Behaviour Merleau-Ponty wrote that "science must be linked to a history of the universe in which the development is discontinuous.” (SdC 150/139) I am arguing that this discontinuity is precisely what we find in expressive movement that at once opens and actualizes possibility, in which there is a peculiar identity yet discontinuity between the moments of movement and the whole of the movement. As Bergson might put it, time does make a difference, discontinuity introduces novelty-only here I want to talk about expressive movement, rather than time. But what does it mean to think of a universe in which expressive movement makes a difference? Earlier I said that The Structure of Behaviour leads us to think of organisms as organizing norms over the lifetime of the species, and humans as organizing new meanings over individual lifetimes_-and Merleau-Ponty calls this organizing "expression." We are beginning to think of the universe not as the unfolding of a system whose law would already have been specified, but rather as a process the beginning and development of which makes a difference in the way that the beginning and development of a life or expression makes a difference. In short, we are led to think of the universe as organizing and expressing its intelligibility over a singular lifetime. To be more concrete, in the first corollary to the third law of motion Newton ${ }^{36}$ proves that a body acted on by two forces describes the diagonal of the parallelogram that would be described by the two forces acting separately. We have to ask: Why does this proof work? Why is the universe susceptible to decomposition along lines we find intelligible? Is it because of an absolute space-time-law that would already specify such intelligibility? No, it is because the universe grows to express such an intelligibility. In following this line of thinking, life, at least expressive movement, once again becomes primary in modelling the intelligibility of the universe.

To put it another way, the emphasis on activity, agency and self-organization in current science, mentioned at the beginning of this paper, would seem to demand a conceptual reversal in which the expressive movement of the universe is primary, and natural law is secondary. Why? Accounting for activity, agency and self-organization in terms of the primacy of an already specified natural law leads to a double conceptual problem. First, conceiving activity, agency and self-organization in this way turns them into epiphenomenal, passive results of law, which is inconsistent with conceiving such phenomena as active, self-organizing 
agencies. Second, if natural law is primary, then we need an account of the ontology and origin of the law, and of the relation between law and that of which it is the law. If, instead, active self-organization is considered primary, if natural law is conceived as an epiphenomenon of a prior movement, or, to put in terms of MerleauPonty's Structure, if we conceive law as a phenomenon expressed by natural process, then the second problem can be resolved, and the first problem is no longer a problem (because active, self-organizing process is primary). The living once again gives us a model of this sort of relation between a process and a law expressed by that process. In How the Leopard Changed Its Spots, Brian Goodwin observes that in higher plants, we find only three basic arrangements of leaves on stems. One might think that these arrangements are determined by a law fixed in advance of plant growth by a genetic program, but Goodwin argues that they are the outcome of tensions inherent in plant growth: growth stresses the outer skin of the plant, and budding is, as it were, the resolution of these stresses; the regular arrangement of leaves on stems is a trace of resolving a stress pattern endogenous to a plant's growth in its environment. ${ }^{37}$ The arrangement of leaves is not the outcome of a fixed law, it expresses the serial rhythm of internal stresses. We make a mistake if we take the law visibly manifest in the final arrangement of leaves as an abstract control mechanism built-in and governing leaf arrangement from the start; rather, the law visible in the grown plant is the expression of a growth process, even if the details of that self-organizing growth are invisible to unaided perception. Likewise, I suggest, with the universe: natural law is the visible expression of a growth process, the selforganization of which is invisible.

A crucial question thus arises: Why is the living movement of the universe, its 'growth', invisible? To add one last controversial thought to the ones above, it is because the universe is for us more like an animal than a plant. When a plant grows we see limbs and organs unfold along a line of growth, but when we watch, for example, a mammal growing we only see development in size, completion and behaviour-changes in degree, not kind. ${ }^{38}$ We see qualitative change in the growth of plants because their gestation from seed is visible to us, while that of the animal is invisible. The gestation of our universe is even more invisible to us, even though its trace is visible in all things. We are like the botanist who realizes that the pattern of leaves in the plant cannot be modelled in terms of the framework now visible in the plant, as that framework is understood by the botanist; rather, the pattern must be modelled in terms of the living growth that gives rise to it. While the botanist can make botanic growth processes visible, through empirical study and conceptual reconstruction of it, this is not empirically possible with the universe as a whole, and much more difficult conceptually, because the growth of the universe gives rise to all of entities and relations that would be part of our conceptual reconstruction of it. Indeed, our tendency is to make the invisible of the universe all too continuous with the universe now visible. For example, we reify presently manifest law and take it as a template for explanation that can be projected back into the inception of the universe. When we model the invisible of the universe on non-living processes that are so visible to us now, the discontinuities that give rise to the visible spatio-temporallawful continuity of our universe are invisible to us. What I am saying instead is that the invisible of the visible intelligibility of the universe is to be modelled on movement that generates its own 
discontinuity — and this sort of expressive movement is characteristic of the living.

${ }^{1}$ On this general issue, see, e.g., R.G. Collingwood, The Idea of Nature (London: Oxford University Press, 1945).

${ }^{2}$ For this point about substance, see L.A. Kosman, "Animals and Other Beings in Aristotle,” in Philosophical Issues in Aristotle's Biology, ed. Allan Gotthelf and James G. Lennox (Great Britain: Cambridge University Press, 1987). Kosman's work in general is helpful in clarifying the centrality of dynamic activity in Aristotle, and the linkage between this activity and living activity.

${ }^{3}$ Cf., e.g., Hans Jonas, The Phenomenon of Life: Toward a Philosophical Biology (New York: Dell Publishing, 1966). G.W.F. Hegel, Phenomenology of Spirit, trans. A.V. Miller (New York: Oxford University Press, 1977), is also notable for arguing that modern skepticism wrongly tries to remodel exteriority in terms of a claimed, purely interior certainty, and Hegel's discussion suggests that the inertness of models is a problem. On Hegel's analysis of reason and the origins of modern skepticism, cf. John Russon, "Hegel's Phenomenology of Reason and Dualism," The Southern Journal of Philosophy 31, no. 1 (1993): 71-96 and Jean Hyppolite, Genesis and Structure of Hegel's Phenomenology of Spirit (Evanston, IL: Northwestern University Press, 1974).

${ }^{4}$ Stephen Jay Gould, The Structure of Evolutionary Theory (Cambridge, Mass.: The Belknap Press of Harvard University Press, 2002), especially chapter 2.

${ }^{5}$ See Brian Goodwin, How the Leopard Changed Its Spots: The Evolution of Complexity (Princeton: Princeton University Press, 2001).
${ }^{6}$ See Robert Rosen, Life Itself : A Comprehensive Inquiry into the Nature, Origin, and Fabrication of Life, Complexity in Ecological Systems Series (New York: Columbia University Press, 1991) and Robert Rosen, Essays on Life Itself, Complexity in Ecological Systems Series (New York: Columbia University Press, 2000). Readers of Bergson will note a parallel between Rosen and Bergson regarding the claim that the closed systems of physics are derivative from open systems.

${ }^{7}$ To give a sample: Alicia Juarrero, Dynamics in Action: Intentional Behavior as a Complex System (Cambridge, MA: MIT Press, 1999); S.L. Hurley, Consciousness in Action (Cambridge, MA: Harvard University Press, 1998); J.A. Scott Kelso, Dynamic Patterns: The Self-Organization of Brain and Behaviour (Cambridge, Mass.: MIT Press, 1999).

${ }^{8}$ Manuel DeLanda, Intensive Science and Virtual Philosophy (London: Continuum, 2002).

9 johnstone.

${ }^{10}$ Renaud Barbaras, "The Movement of the Living as the Originary Foundation of Perceptual Intentionality," in Naturalizing Phenomenology: Issues in Contemporary Phenomenology and Cognitive Science, ed. Jean Petitot et al. (Stanford: Stanford University Press, 1999), 525-538.

${ }^{11}$ Cf. Maxine Sheets-Johnstone, The Primacy of Movement (Amsterdam: John Benjamins Publishing Company, 1999).

12 The question of the coherence of MerleauPonty's works thus echoes the issue of discontinuity and continuity of the universe addressed below.

${ }^{13}$ Maurice Merleau-Ponty, La Structure du comportement (Paris: Quadrige/Presses Universitaires de France, 1942); Maurice 
Merleau-Ponty, The Structure of Behaviour, trans. Alden L. Fisher (London: Methuen, 1965). Hereinafter $S d C$ [French pg\#]/[English pg\#].

${ }^{14}$ Maurice Merleau-Ponty, Phénoménologie de la perception (Paris: Galimard, 1945); Maurice Merleau-Ponty, Phenomenology of Perception, trans. Colin Smith (New Jersey: The Humanities Press, 1962). Hereinafter PhP [French pg\#]/[English pg\#].

${ }^{15}$ Maurice Merleau-Ponty, Le Visible et l'invisble (Paris: Galimard, 1979); Maurice Merleau-Ponty, The Visible and the Invisible, trans. Alphonso Lingis (Evanston, IL: Northwestern University Press, 1968).

${ }^{16} \mathrm{Cf}$., e.g., the oft cited working note of July 1959 in The Visible and the Invisible, pg. 253 in the French, pg. 200 in the English.

${ }^{17}$ SdC 223/206, Fisher's translation modified. Cf. SdC 138/127, where MerleauPonty argues that behaviour is neither a thing nor an idea.

${ }^{18}$ Cf. DeLanda, Intensive Science and Virtual Philosophy .

${ }^{19}$ In more detail, Merleau-Ponty argues that there is a sort of meta-structure that downwardly integrates human, vital and physical structures in one natural whole (SdC 142-143, 155-7/132, 143-5). And Merleau-Ponty often writes of vital and physical systems as expressing structures or ideas. For example, laws in a physical system express a structure (SdC 148149/138) and movements of the organism express the idea under which we subsume them (SdC 165/152).

20 "If Gestalt theory is not "vitalist," it would nevertheless introduce anthropomorphism and finality into physics...” (SdC 52/49); “...the pleasure of the success was appealed to anthropomorphically in order to explain the fixation of useful reactions" (SdC 103/94).
${ }^{21}$ Leonard Lawlor, "The End of Phenomenology: Expressionism in Deleuze and Merleau-Ponty," Continental Philosophy Review 31 (1998): 15-34.

${ }^{22}$ In more detail: If, as Merleau-Ponty writes in his analysis of the transcendental field, reflection is not "a return to universal reason" but is something more radical that is "anticipated in unreflective experience," "a creative operation which itself participates in the facticity of that experience" (PhP $74 / 61$ ), it is because reflection is expressive. And if reflection must grasp its sense through the unreflective fund of experience that is "a kind of original past" that has never been present (PhP 280/242), it can do so only because that original past itself turns from non-sense to sense in the sort of transition accomplished by expression.

${ }^{23}$ Bernhard Waldenfels, "The Paradox of Expression,” in Chiasms: Merleau-Ponty's Notion of Flesh, ed. Fred Evans and Leonard Lawlor (Albany: SUNY Press, 2000), 89102.

${ }^{24}$ Cf. On Generation and Corruption, I,4; Physics 192b15.

${ }^{25}$ Cf. Henri Bergson, Matter and Memory, trans. N.M. Paul and W.S. Palmer (New York: Zone Books, 1991), especially pg. 202 for this and the following points about movement.

${ }^{26}$ Bernhard Waldenfels, "The Paradox of Expression,” in Chiasms: Merleau-Ponty's Notion of Flesh, ed. Fred Evans and Leonard Lawlor (Albany: SUNY Press, 2000), 89102.

${ }^{27}$ For example, we could show that a gesture of surprise is what happens when a wave of movement crashes through a body that needs to selectively transform movement; the phenomenon of expression descriptively corresponds to a sort of internal transformation or complication of 
movement. But in this paper I am seeking something deeper.

${ }^{28}$ The strategy of taking a clue from Hegel is not as strange as it seems. As Lawlor shows in his article on expression, Hyppolite's study of Hegel's logic (Logique et existence) is in the background of Deleuze's Logic of Sense. And at crucial points in the Structure of Behaviour Merleau-Ponty draws on Hegel and Hyppolite. (Notably Hyppolite's article "Vie et prise de conscience de la vie dans la philosophie Hégélienne d'Iéna.”) As Lawlor notes, Hyppolite calls Hegel's concept "sens." So how does Hegel arrive at sens? Like Merleau-Ponty, Hegel criticises the logic of essence and reflection, which identifies every visible phenomenon as the reflection of an invisible ground. The problem for Hegel (which is articulated in the "Doctrine of Essence" in his Science of Logic) is that reflective thinking has to pack every visible difference into the invisible ground, so the difference between the visible and the invisible collapses, leading to the absurdity of a ground that is the same as what it grounds. To protect the difference between the visible show of things and its invisible ground, what is required is a ground that does not resemble what it grounds, and this means thinking of existence as self-grounding, self-actualizing. Reflection is thus rooted not in a transcending consciousness, but in an existence that reflects its own possibilities. But Hegel argues that deep logical and ontological absurdities follow if we conceive the possible as a storehouse of possibilities waiting to be unwound, if we solve the problem of self-actualization by having the actual reflect a possible that is already, as it were, given. It is at this point that Hegel argues that a logic of the concept, of sense, is required. What is distinctive of Hegel's logic of sense is that in contrast to the actualization of a ready-made possible, the becoming of sense is a self-conceptual process that produces the possible that enables new sense. In this way Hegel converges with Bergson on the possible.

${ }^{29}$ For these point see Bergson, Matter and Memory; Henri Bergson, Creative Evolution, trans. Arthur Mitchell (Mineola, N.Y.: Dover, 1998); and the study of possibility collected in English in Henri Bergson, The Creative Mind: An Introduction to Metaphysics, trans. Mabelle L. Andison (New York: Citadel Press, 2002).

${ }^{30}$ English as She is Spoke is the title of a Portugese-English phrasebook by a Portugese man who famously, as the title of his work suggests, did not know how to speak English. Apparently this book was of some inspiration to Joyce.

31 The difficulty is that with Joyce we have a case in which actuality is not subsequent to possibility, but contemporaneous with and creative of it, whereas in our usual concept possibility precedes its actualization. What Joyce actually does with language redefines the possibility of Joycean English. Just as the evolutionist would insist that a butterfly is not the actualization of a possibility already foretold by a pre-defined space of biological possibilities, but the contingent result of evolving biological actualities, here too we should insist that Joyce's moves are not foretold by the possibilities of English. Thus we must insist that what he actualizes is not subsequent to already defined possibilities, but creates the possibilities that it actualizes in the very moment of actualization, and defines the space of possibilities by not having create other possibilities.

32 This suggests a criticism of Delanda's appeal to information theory in Intensive 
Science, Virtual Philosophy, that Delanda is too quickly eliding sense and information.

${ }^{33}$ Cf. the works collected in Alfred I.

Tauber, ed. Organism and the Origins of

Self, Boston Studies in the Philosophy of

Science, vol. 129 (Dordrecht, Netherlands:

Kluwer, 1991); also see Irun R. Cohen,

"Discrimination and Dialogue in the

Immune System," Immunology 12 (2000):

215-219 and Leon Chernyak and Alfred I.

Tauber, "Concerning Individuality," Biology and Philosophy 7 (1992): 489-499.

34 And this would mean we have to wait, as Bergson might put it, to see what the self is.

${ }^{35}$ L.W. Buss, The Evolution of Individuality (Princeton: Princeton University Press, 1987).

36 “A body acted on by [two] forces acting jointly describes the diagonal of a paralleogram in the same time in which it would describe the sides if the forces were acting separately” (Isaac Newton, The Principia: Mathematical Principles of Natural Philosophy, trans. Bernard Cohen and Anne Whitman (Berkeley: University of California Press, 1999)).

${ }^{37}$ Brian Goodwin, How the Leopard Changed Its Spots: The Evolution of Complexity (Princeton: Princeton University Press, 2001), esp. chapters 4 and 5.

${ }^{38}$ Cf. G.W.F. Hegel, Philosophy of Mind, trans. William Wallace (Oxford: Clarendon Press, 1971), §381. 